\title{
Word Finding Difficulty Test Design and Standardization
}

\author{
Abstract \\ OBJECTIVE: The aim of this study is to design a new test for assessment of word \\ finding difficulty in children in order to better assess and manage this problem.
}

SUBJECTS AND METHODS: The test was designed and included pictures of different semantic groups. It was revised by Phoniatric experts. Then it was applied on a group of 50 normal children and a group of 25 DLD children with age range of 5-10 years with average or below average IQ.

RESULTS: The test consists of 7 sections. Validity of the test was examined by content validity, contrasted group validity and internal consistency validity. The results showed significant difference between scores of normal children and DLD children in all sections of the test.

CONCLUSION: Word finding difficulty test is suitable and easy applicable to assess word finding difficulty in children. It will help in accurate assessment of these children and therefore putting suitable plan for intervention.

\section{Introduction}

The patient with word finding difficulty presents a common and challenging clinical problem. The complaint of word finding difficulty covers a wide range of clinical phenomena and may signify a number of distinct pathophysiological processes. Word finding difficulties are defined as reduced ability to retrieve and /or produce a specific word in response to a stimulus or situation. Actually, such difficulties impede oral communication and reading as both of which require efficient retrieval of words from mental lexicon (Faust et al., 1997).In case of dysphasia, word finding deficit is defined as a profound difficulty in coming up with words in the course of a given linguistic activity. This definition presumes that a word being sought was originally known by the patient with dysphasia and the difficulty in retrieval is not due to failed articulation (Connor and Obler, 2002). Word finding difficulty is not uncommon problem. Dockrell et al., (1998) found that $23 \%$ of children in language support services were identified to have word finding difficulty while the figure may be around $50 \%$ for learning disabled children (German, 1998).

Leonard et al. (1983) discussed two possible underlying causes for word finding problems in children: The first, the storage hypothesis, proposed that the child has not learned the names for lexical items adequately. That yields less accurate and slower naming. The second hypothesis focused instead on retrieval. The claim here is the stored lexical representations are similar to normal language development. But the information or names are less accessible.

Word Finding difficulties have been identified and described among Children who have learning disabilities (LD), specific language impairment (SLI) and attention deficit hyperactive disorder (ADHD) (German and Newman, 2005).Also aphasic patients have severe word-finding difficulty. The anomia in anomic aphasia is characterized by circumlocution and awareness of retrieval failure (Howard and Gatehouse, 2006). There are many tests designed for assessment of word finding difficulty. Some of these tests were designed for assessment of word 
finding difficulty in children as Test of Word Finding -Second Edition (TWF2 German 2000b), Arabic-Test of Word Finding Difficulty (Khedr et al., 2009) and Test of word naming speed in Specific Language Impairment Children (Adel et al., 2014). Other tests were designed for assessment of word finding difficulty in adults as Philadelphia Naming Test(PNT)(Roach et al., 1996) and Northwestern Naming Battery (NNB) (Thompson et al., 2012). So, there is a need for a test which is suitable and easy applicable to assess word finding difficulty in Arabic speaking children. It can be applied in children with specific language impairment or any other condition with word finding difficulty in urban and rural communities. It will help in accurate assessment of these children and therefore putting suitable plan for intervention.

Aim of the work: The aim of this work is to design a new test for evaluation of word finding difficulty in children and investigate its validity and reliability in order to better assess and manage this problem.

Subjects and MethodsThis study was done to design a new test for evaluation of word finding difficulty in children in the following steps:

I-Word finding difficulty test design:Word finding difficulty test was designed at our Phoniatric Unit at Sohag University Hospital. The test consists of pictures of different semantic groups, categories, professions (jobs), verbs and shapes. These pictures were chosen to be suitable for the environment at Sohag governorate that gathers both urban and rural features. They were graduated in difficulty from common objects (that the child encounter and deal with so frequently in the daily activities such as car, dog and tomatoes) to less common objects (that the child encounter and deal with less frequently in the daily activities such as train, horse and carrots) to rare objects (that the child doesn't encounter and deal with frequently in the daily activities such as crocodile and cart).

\section{II-Testing validity of the test}

1. Content validity: After the initial choice of different pictures and items of the test, it was presented at the meeting of Phoniatric unit at Sohag University Hospital in presence of our Phoniatric experts. Correction and the final choice of pictures and items were done according to the opinion of Phoniatric experts of Sohag University till reaching the last form that applied on children.

2. Contrasted group validity:The test was applied at Phoniatric Unit, Sohag University Hospital.It was applied on 2 groups:

1.Group I (controls) included 50 normally developed children with an age range of 5-10 years. The group was divided into 2 subgroups according to the age as follow:Subgroup Ia: with age range from 5 years to 7 years and 6 months (25 children).Subgroup Ib: with age range of more than 7 years and months to 10 years (25children).

2.Group II (cases) included 25 children with delayed language development (with average or below average IQ) with an age range of 5-10 years. It was also divided into 2 subgroups as in group 1.

The selected subjects were subjected to the protocol of language assessment which is applied at Phoniatric Unit, Sohag University Hospital as follow: Full history taking, general examination, vocal tract examination, ear and nose examination and neurological assessment.Evaluation of IQ using Stanford Binet Intelligence Scale (fifth Edition) (Hanoura, 2002). 
Audiological evaluation. Language evaluation using the Arabic language test and articulation test (Kotby et al., 1985\&1995).

Informed written consent was taken from the parents of the child before application of the test.

3.Internal consistency validity: It measures test homogeneity.The internal structure of the test is examined by making correlation between language age of the child and the score of different sections of the test as well as total score of the test.

All normative data obtained in the result section was analyzed by

\section{Results}

This is the results of a case control study that was conducted at Phoniatric Unit, Sohag University Hospital.The subjects were subjected to the word finding difficulty test. The response was observed for accuracy and time and scored accordingly. The score differ from familiar items to less familiar to rare as in table (1).

I-Word finding difficulty test design: The test consists of 7 sections as follow: Section 1: picture naming nouns:This section includes pictures of 10 different semantic groups (body parts, animals, birds, vegetables, fruits, transportations, clothes, electric devices, furniture and private tools).In each group, there are 3 pictures the first is familiar, the second is less familiar and the third is rare. There is another picture as an example for each semantic group shown to the subject at the start of each semantic group. So the total number of pictures of this section (including the examples) is 40 pictures.Each subject was asked to name the picture. For each semantic group, the example picture was presented first and asking (What is this?).The response must be the name of the picture. Then started to present the rest of the semantic group to the subject starting with the familiar, then less familiar and lastly the rare pictures.At the end of the section, the total score for this section was calculated. The maximal score for that section is 180 points.

Table (1): The scoring system for items of word finding difficulty test:

\begin{tabular}{|c|c|c|c|}
\hline Response timing and accuracy & $\begin{array}{l}\text { Familiar items } \\
\text { score }\end{array}$ & $\begin{array}{l}\text { Less familiar } \\
\text { items score }\end{array}$ & Rare items score \\
\hline $\begin{array}{l}\text { Immediate (within } 4 \text { seconds) and accurate } \\
\text { response. }\end{array}$ & 4 & 6 & 8 \\
\hline Immediate response with acceptable error. & 2 & 4 & 6 \\
\hline Immediate response but inaccurate. & $\mathbf{0}$ & $\mathbf{0}$ & $\mathbf{0}$ \\
\hline $\begin{array}{l}\text { Delayed response (5-10 seconds) and } \\
\text { accurate. }\end{array}$ & 3 & 5 & 7 \\
\hline Delayed response with acceptable error. & 1 & 3 & 5 \\
\hline Delayed and inaccurate response & $\mathbf{0}$ & $\mathbf{0}$ & $\mathbf{0}$ \\
\hline No or wrong response & $\mathbf{0}$ & $\mathbf{0}$ & $\mathbf{0}$ \\
\hline
\end{tabular}


Section 2: picture naming categories:In this section, naming of different categories (such as body parts, animals and vegetables) was tested. First an example was presented to the subject and asking (what is the name of this category?) the response must be the name of the category not the individual things as (kitchen tools). Then started to test different categories starting with the familiar, then less familiar and lastly the rare. This section includes 12 items and one example item. Each item consists of 4 pictures belonging to the same category. These different categories are classified into:Familiar group (4 items): including body parts, animals, birds and vegetables, Less familiar group (4 items): including fruits, Clothes, transportations and electric devices and Rare group (4 items): including furniture, writing tools, private tools and jobs. At the end of the section, the total score for this section was calculated. The maximal score for that section is 72 points.

Section 3: picture naming professions: In this section, naming of different professions (jobs) was tested. First an example picture was presented to the subject and asking (What is the job of that person? And the response must be the name of the job as she is a nurse.). Then started to test different jobs starting with the familiar, then less familiar and lastly the rare. This section includes 12 items and one example item. These jobs are also classified into: Familiar group (4 items) including farmer, teacher, doctor and butcher.Les familiar group (4 items) including policeman, carpenter, barber and Chef .Rare group (4 items) including engineer, builder, plumber and baker. At the end of the section, the total score for this section was calculated. The maximal score for that section is 72 points.

Section 4: picture naming verbs:In this section naming of different verbs (actions) was tested. First an example picture was presented to the subject and asking (What is the person doing? And the response must be the verb (action) such as (She is running.). Then started to test different verbs starting with the familiar, then less familiar and lastly the rare through presenting a picture to the subject and ask him to name it. This section includes 14 items and one example item.The verbs are also classified into:Familiar verbs (5 items) including drink, sleep, read, laugh and wash hand.Less familiar verbs (5 items) including coloring, pray, swim, play and combing hair.Rare verbs (4 items) including fly, jump, harvest and cut wood.At the end of the section, the total score for this section was calculated. The maximal score for that section is 82 points.

Section 5:

naming of numbers, days and shapes: In this section, naming of numbers, days of the week and the shapes was tested. This section includes 12 items as follow: Naming of numbers as familiar items (4 items): 4, 7, 9 and 5.Naming of days as less familiar items (4 items): Tuesday, Sunday, Thursday and Monday. Naming of shapes as rare items (4 items): triangle, square, star and circle. The picture of the shape was presented to the subject and asking to name it. Numbers and days were tested without pictures.At the end of the section, the total score for this section was calculated. The maximal score for that section is 72 points. Section 6: Sentence completion naming In this section, the ability to complete a sentence with the appropriate word was tested. First the subject was shown an example. A sentence was said and the subject was asked to complete the sentence with the appropriate word as (Mama cuts the meat with the......knife.).Then started to test different sentences starting with the familiar, then less familiar and lastly the rare. This section includes 11 items and one example item. Also these sentences were classified into familiar (4), less familiar (4) and rare (3). At the end of the section, the total score for this section was calculated. The maximal score for that section is 64 points.

Section 7: Description naming: In this section, the ability to name something from description was tested .First the subject was shown an example (What is the thing with which 
we write? The answer is a pen.). Then started to test different sentences starting with the familiar, then less familiar and lastly the rare. This section includes 10 items and one example item.These sentences were classified into familiar (4), less familiar (3) and rare (3). At the end of the section, the total score for this section was calculated. The maximal score for that section is 58 points.

At the end of the test, the score for each section was calculated. Results were presented into a graph .Also the total score of the whole test was calculated. The maximal total score is 600 points.

\section{II-Evidence of validity of the test}

1. Content validity:Phoniatric experts of Sohag University Hospital examined the content validity of the test. The final choice of pictures and items of the test was done according to the opinion of Phoniatric experts till reaching the last form that applied on children.

2.Contrasted group validity:Both groups of the study (controls and cases) were compared as regard age, gender and IQ as in table (2).There was no significant difference between both groups.

Table (2): Comparison between both groups as regard age, gender and IQ

\begin{tabular}{|c|c|c|c|}
\hline P value & $\begin{array}{c}\text { Controls(I) } \\
\mathbf{N}=50\end{array}$ & $\begin{array}{c}\text { Cases(II) } \\
\mathbf{N}=25\end{array}$ & Variable \\
\hline 0.13 & $7.44 \pm 1.50$ & $6.87 \pm 1.56$ & $\begin{array}{l}\text { Age/year } \\
\text { Mean } \pm \text { SD }\end{array}$ \\
\hline 0.39 & $\begin{array}{l}19(38.00 \%) \\
31(62.00 \%)\end{array}$ & $\begin{array}{c}7(28.00 \%) \\
18(72.00 \%)\end{array}$ & $\begin{array}{l}\text { Gender } \\
\text { Females } \\
\text { Males } \\
\end{array}$ \\
\hline 0.09 & $85.68 \pm 6.00$ & $83.16 \pm 6.15$ & $\begin{array}{l}\mathbf{I Q} \\
\text { Mean } \pm \text { SD }\end{array}$ \\
\hline
\end{tabular}

$*=\mathrm{P}<0.05$ (significant) and $* *=\mathrm{P}<0.001$ (highly significant).

Both groups (controls and cases) were compared as regard scores of each section of the word finding difficulty test as in table (3). There was a highly significant difference in all sections of the test.

Table (3): Comparison between both groups as regard the scores in all sections of the test.

\begin{tabular}{|c|c|c|c|}
\hline P value & $\begin{array}{c}\text { Controls(I) } \\
\mathbf{N}=50\end{array}$ & $\begin{array}{c}\text { Cases(II) } \\
\mathrm{N}=25\end{array}$ & Variable \\
\hline$<0.0001 * *$ & $166.96 \pm 11.76$ & $99.96 \pm 13.98$ & $\begin{array}{l}\text { Picture naming noun } \\
\text { Mean } \pm \text { SD }\end{array}$ \\
\hline$<0.0001 * *$ & $55.34 \pm 10.23$ & $22.56 \pm 8.51$ & $\begin{array}{l}\text { Picture naming categories } \\
\text { Mean } \pm \text { SD }\end{array}$ \\
\hline$<0.0001 * *$ & $61.04 \pm 10.90$ & $34.12 \pm 6.48$ & $\begin{array}{l}\text { Picture naming profession } \\
\text { Mean } \pm \text { SD }\end{array}$ \\
\hline$<0.0001 * *$ & $81.34 \pm 1.77$ & $51.16 \pm 7.51$ & $\begin{array}{l}\text { Picture naming verb } \\
\text { Mean } \pm \text { SD }\end{array}$ \\
\hline$<0.0001 * *$ & $69.98 \pm 4.68$ & $38.24 \pm 12.35$ & $\begin{array}{l}\text { Naming of no. \&days } \\
\text { Mean } \pm \text { SD }\end{array}$ \\
\hline$<0.0001 * *$ & $61.86 \pm 2.53$ & $39.36 \pm 6.47$ & $\begin{array}{l}\text { Sentence completion } \\
\text { Mean } \pm \text { SD }\end{array}$ \\
\hline$<0.0001^{* * *}$ & $55.62 \pm 2.71$ & $33.4 \pm 8.05$ & $\begin{array}{l}\text { Description naming } \\
\text { Mean } \pm \text { SD }\end{array}$ \\
\hline$<0.0001 * *$ & $552.12 \pm 37.20$ & $318.8 \pm 51.12$ & $\begin{array}{l}\text { Total } \\
\text { Mean } \pm \text { SD }\end{array}$ \\
\hline
\end{tabular}


SOHAG MEDICAL JOURNAL Vol. 22 No.1 Jan 2018
Word Finding Difficulty Test Design and Standardization Gerges Wasfy Gerges Farah

Both groups (controls and cases) were divided into 2 subgroups according to the age. Group I (controls) was divided into subgroup Ia with age range of 5years to 7 years and 6 months and subgroup $\mathrm{Ib}$ with age range more than 7 years and 6 months to 10 years. Also, group II (cases) was divided into subgroups( IIa\&IIb) with the same age range as subgroups (Ia\&Ib). Both subgroups Ia and IIa were compared as regard scores of different sections of the word finding difficulty test as in table (4).There was a highly significant difference in all sections of the test.

Table (4): Comparison between subgroups Ia and IIa as regard scores in all sections of the test.

\begin{tabular}{|c|c|c|c|}
\hline$P$ value & $\begin{array}{c}\text { Controls(Ia) } \\
\mathrm{N}=25\end{array}$ & $\begin{array}{c}\text { Cases(IIa) } \\
\mathrm{N}=15\end{array}$ & Variable \\
\hline$<0.0001 * *$ & $158.36 \pm 9.91$ & $92.67 \pm 12.61$ & $\begin{array}{l}\text { Picture naming noun } \\
\text { Mean } \pm \text { SD }\end{array}$ \\
\hline$<0.0001 * *$ & $47.32 \pm 8.12$ & $20.87 \pm 10.32$ & $\begin{array}{l}\text { Picture naming categories } \\
\text { Mean } \pm \text { SD }\end{array}$ \\
\hline$<0.0001 * *$ & $53.68 \pm 10.66$ & $32.07 \pm 5.89$ & $\begin{array}{l}\text { Picture naming profession } \\
\text { Mean } \pm \text { SD }\end{array}$ \\
\hline$<0.0001 * *$ & $80.68 \pm 2.34$ & $47.07 \pm 5.29$ & $\begin{array}{l}\text { Picture naming verb } \\
\text { Mean } \pm \text { SD }\end{array}$ \\
\hline$<0.0001 * *$ & $67.96 \pm 6.02$ & $31.8 \pm 10.17$ & $\begin{array}{l}\text { Naming of no. \&days } \\
\text { Mean } \pm \text { SD }\end{array}$ \\
\hline$<0.0001 * *$ & $60.6 \pm 2.82$ & $36.80 \pm 6.71$ & $\begin{array}{l}\text { Sentence completion } \\
\text { Mean } \pm \text { SD }\end{array}$ \\
\hline$<0.0001 * *$ & $54.00 \pm 2.86$ & $28.93 \pm 6.87$ & $\begin{array}{l}\text { Description naming } \\
\text { Mean } \pm \text { SD }\end{array}$ \\
\hline$<0.0001 * *$ & $522.6 \pm 29.92$ & $290.2 \pm 43.66$ & $\begin{array}{l}\text { Total } \\
\text { Mean } \pm \text { SD }\end{array}$ \\
\hline
\end{tabular}

Both subgroups Ib and IIb were compared as regard scores of different sections of the word finding difficulty test as in table (5). There was a highly significant difference in all sections of the test.

Table (5): Comparison between subgroups Ib and IIb as regard scores in all sections of the test.

\begin{tabular}{|c|c|c|c|}
\hline P value & $\begin{array}{l}\text { Controls(Ib) } \\
\quad \mathrm{N}=\mathbf{2 5}\end{array}$ & $\begin{array}{c}\text { Cases(IIb) } \\
\mathrm{N}=10\end{array}$ & Variable \\
\hline$<0.0001 * *$ & $175.56 \pm 5.47$ & $110.9 \pm 7.22$ & $\begin{array}{l}\text { Picture naming noun } \\
\text { Mean } \pm \text { SD }\end{array}$ \\
\hline$<0.0001 * *$ & $63.36 \pm 3.72$ & $25.1 \pm 3.93$ & $\begin{array}{l}\text { Picture naming categories } \\
\text { Mean } \pm \text { SD }\end{array}$ \\
\hline$<0.0001 * *$ & $68.4 \pm 4.02$ & $37.2 \pm 9.36$ & $\begin{array}{l}\text { Picture naming profession } \\
\text { Mean } \pm \text { SD }\end{array}$ \\
\hline$<0.0001^{* * *}$ & $82.00 \pm 0$ & $57.3 \pm 6.09$ & $\begin{array}{l}\text { Picture naming verb } \\
\text { Mean } \pm \text { SD }\end{array}$ \\
\hline$<0.0001 * *$ & $72 \pm 0$ & $47.9 \pm 8.54$ & $\begin{array}{l}\text { naming of no.\& days } \\
\text { Mean } \pm \text { SD }\end{array}$ \\
\hline$<0.0001 * *$ & $63.12 \pm 1.36$ & $43.2 \pm 3.82$ & $\begin{array}{l}\text { Sentence completion } \\
\text { Mean } \pm \text { SD }\end{array}$ \\
\hline$<0.0001^{* *}$ & $57.24 \pm 1.16$ & $40.1 \pm 4.01$ & $\begin{array}{l}\text { Description naming } \\
\text { Mean } \pm \text { SD }\end{array}$ \\
\hline$<0.0001 * *$ & $584.64 \pm 10.71$ & $361.7 \pm 24.35$ & $\begin{array}{l}\text { Total } \\
\text { Mean } \pm \text { SD }\end{array}$ \\
\hline
\end{tabular}

Both subgroups of group I (controls) Ia and Ib were compared as regard scores of different sections of the word finding difficulty test as in table (6).There was highly significant difference in all sections of the test. 
SOHAG MEDICAL JOURNAL Vol. 22 No.1 Jan 2018
Word Finding Difficulty Test Design and Standardization Gerges Wasfy Gerges Farah

Table (6): Comparison between subgroups Ia and Ib as regard the scores in all sections of the test.

\begin{tabular}{|c|c|c|c|}
\hline$P$ value & $\begin{array}{c}\text { Controls (Ib) } \\
\mathrm{N}=25\end{array}$ & $\begin{array}{c}\text { Controls (Ia) } \\
\mathrm{N}=\mathbf{2 5}\end{array}$ & Variable \\
\hline$<0.0001 * *$ & $175.56 \pm 5.47$ & $158.36 \pm 9.91$ & $\begin{array}{l}\text { Picture naming noun } \\
\text { Mean } \pm \text { SD }\end{array}$ \\
\hline$<0.0001 * *$ & $63.36 \pm 3.72$ & $47.32 \pm 8.12$ & $\begin{array}{l}\text { Picture naming category } \\
\text { Mean } \pm \text { SD }\end{array}$ \\
\hline$<0.0001 * *$ & $68.4 \pm 4.02$ & $53.68 \pm 10.66$ & $\begin{array}{l}\text { Picture naming profession } \\
\text { Mean } \pm \text { SD }\end{array}$ \\
\hline $0.007 * *$ & $82.00 \pm 0$ & $80.68 \pm 2.34$ & $\begin{array}{l}\text { Picture naming verb } \\
\text { Mean } \pm \text { SD }\end{array}$ \\
\hline $0.002 * *$ & $72 \pm 0$ & $67.96 \pm 6.02$ & $\begin{array}{l}\text { Naming of no.\& days } \\
\text { Mean } \pm \text { SD }\end{array}$ \\
\hline $0.0002 * *$ & $63.12 \pm 1.36$ & $60.6 \pm 2.82$ & $\begin{array}{l}\text { Sentence completion } \\
\text { Mean } \pm \text { SD }\end{array}$ \\
\hline$<0.0001 * *$ & $57.24 \pm 1.16$ & $54.00 \pm 2.86$ & $\begin{array}{l}\text { Description naming } \\
\text { Mean } \pm \text { SD }\end{array}$ \\
\hline$<0.0001 * *$ & $584.64 \pm 10.71$ & $522.6 \pm 29.92$ & $\begin{array}{l}\text { Total } \\
\text { Mean } \pm \text { SD }\end{array}$ \\
\hline
\end{tabular}

$*=\mathrm{P}<0.05$ (significant) and $* *=\mathrm{P}<0.001$ (highly significant).

Both subgroups of group II (cases) (IIa and IIb) were compared as regard scores of different sections of the word finding difficulty test as in table (7). There was highly significant difference in sections $(1 \& 4 \& 5 \& 7)$ and total score with significant difference in section (6) and no significant difference in section $(2 \& 3)$.

Table (7): Comparison between subgroups IIa and IIb as regard the scores in all sections of the test.

\begin{tabular}{|c|c|c|l|}
\hline P value & $\begin{array}{c}\text { cases(IIb) } \\
\mathbf{N}=10\end{array}$ & $\begin{array}{c}\text { Cases(IIa) } \\
\mathbf{N}=\mathbf{1 5}\end{array}$ & Variable \\
\hline $\mathbf{0 . 0 0 0 4} * *$ & $\mathbf{1 1 0 . 9} \pm 7.22$ & $\mathbf{9 2 . 6 7} \pm \mathbf{1 2 . 6 1}$ & $\begin{array}{l}\text { Picture naming noun } \\
\text { Mean } \pm \text { SD }\end{array}$ \\
\hline $\mathbf{0 . 1 5}$ & $\mathbf{2 5 . 1} \pm \mathbf{3 . 9 3}$ & $\mathbf{2 0 . 8 7} \pm \mathbf{1 0 . 3 2}$ & $\begin{array}{l}\text { Picture naming categories } \\
\text { Mean } \pm \text { SD }\end{array}$ \\
\hline $\mathbf{0 . 0 5 1}$ & $\mathbf{3 7 . 2} \pm \mathbf{9 . 3 6}$ & $\mathbf{3 2 . 0 7} \pm \mathbf{5 . 8 9}$ & $\begin{array}{l}\text { Picture naming profession } \\
\text { Mean } \pm \text { SD }\end{array}$ \\
\hline $\mathbf{0 . 0 0 0 2} * *$ & $\mathbf{5 7 . 3} \pm \mathbf{6 . 0 9}$ & $\mathbf{4 7 . 0 7} \pm \mathbf{5 . 2 9}$ & $\begin{array}{l}\text { Picture naming verb } \\
\text { Mean } \pm \text { SD }\end{array}$ \\
\hline $\mathbf{0 . 0 0 0 4 * *}$ & $\mathbf{4 7 . 9} \pm \mathbf{8 . 5 4}$ & $\mathbf{3 1 . 8} \pm \mathbf{1 0 . 1 7}$ & $\begin{array}{l}\text { naming of no.\& days } \\
\text { Mean } \pm \text { SD }\end{array}$ \\
\hline $\mathbf{0 . 0 1 *}$ & $\mathbf{4 3 . 2} \pm \mathbf{3 . 8 2}$ & $\mathbf{3 6 . 8 0} \pm \mathbf{6 . 7 1}$ & $\begin{array}{l}\text { Sentence completion } \\
\text { Mean } \pm \text { SD }\end{array}$ \\
\hline $\mathbf{0 . 0 0 0 1 * *}$ & $\mathbf{4 0 . 1} \pm \mathbf{4 . 0 1}$ & $\mathbf{2 8 . 9 3} \pm \mathbf{6 . 8 7}$ & $\begin{array}{l}\text { Description naming } \\
\text { Mean } \pm \text { SD }\end{array}$ \\
\hline 0.0001** & $\mathbf{3 6 1 . 7} \pm \mathbf{2 4 . 3 5}$ & $\mathbf{2 9 0 . 2} \pm \mathbf{4 3 . 6 6}$ & $\begin{array}{l}\text { Total } \\
\text { Mean } \pm \text { SD }\end{array}$ \\
\hline
\end{tabular}

3.Internal consistencya vlidity: It measures test homogeneity. It was examined by making correlation between language age of the child and the score of different sections of the test as well as total score of the test.

Correlation between receptive language age of the cases and their scores in different sections of the test was done as in table (8). There was significant positive correlation as regard section (1) and highly significant positive correlation as regard section (2) and (3) with no significant correlation as regard other sections of the test. 
SOHAG MEDICAL JOURNAL

Vol. 22 No.1 Jan 2018
Word Finding Difficulty Test Design and Standardization Gerges Wasfy Gerges Farah

Table (8): correlation between receptive language age and scores of different sections of the test in cases.

\begin{tabular}{|l|c|l|}
\hline P value & Correlation co-efficient & Variable \\
\hline $\mathbf{0 . 0 4} *$ & $\mathbf{0 . 4 1}$ & Picture naming noun \\
\hline $\mathbf{0 . 0 0 6} * *$ & $\mathbf{0 . 5 3}$ & Picture naming category \\
\hline $\mathbf{0 . 0 0 1} * *$ & $\mathbf{0 . 6 4}$ & Picture naming profession \\
\hline $\mathbf{0 . 8 1}$ & $\mathbf{- 0 . 0 5}$ & Picture naming verb \\
\hline $\mathbf{0 . 4 1}$ & $\mathbf{0 . 1 7}$ & naming of no.\& days \\
\hline $\mathbf{0 . 6 3}$ & $\mathbf{0 . 1 0}$ & Sentence completion \\
\hline $\mathbf{0 . 3 3}$ & $\mathbf{0 . 2 0}$ & Description naming \\
\hline $\mathbf{0 . 0 7}$ & $\mathbf{0 . 3 5}$ & Total \\
\hline \multicolumn{2}{|c|}{} & $* \mathrm{P}<0.05$ (significant) and $* *=\mathrm{P}<0.001$ (highly significant). \\
\hline
\end{tabular}

Correlation between expressive language age of cases and their scores of different sections of the test was done as in table (9). There was highly significant positive correlation as regard section (3) with no significant correlation as regard other sections of the test.

Table (9): correlation between expressive language age and scores of different sections of the test in cases.

\begin{tabular}{|l|c|l|}
\hline P value & Correlation co-efficient & Variable \\
\hline $\mathbf{0 . 1 5}$ & $\mathbf{0 . 2 9}$ & Picture naming noun \\
\hline $\mathbf{0 . 0 8}$ & $\mathbf{0 . 3 5}$ & Picture naming categories \\
\hline $\mathbf{0 . 0 0 3}$ & $\mathbf{0 . 5 7}$ & Picture naming profession \\
\hline $\mathbf{0 . 3 7}$ & $\mathbf{- 0 . 1 9}$ & Picture naming verb \\
\hline $\mathbf{0 . 8 6}$ & $\mathbf{0 . 0 4}$ & naming of no.\& days \\
\hline $\mathbf{0 . 6 9}$ & $\mathbf{0 . 0 8}$ & Sentence completion \\
\hline $\mathbf{0 . 9 1}$ & $\mathbf{0 . 0 2}$ & Description naming \\
\hline $\mathbf{0 . 3 4}$ & $\mathbf{0 . 2 0}$ & Total \\
\hline \multicolumn{2}{|c|}{$*=\mathrm{P}<0.05$ (significant) and ${ }^{* *}=\mathrm{P}<0.001$ (highly significant). } \\
\hline
\end{tabular}

Correlation between total language age of cases and their scores of different sections of the test was done as in table (10).There was no significant correlation as regard all sections of the test.

Table (10): correlation between total language age and scores of different sections of the test in cases.

\begin{tabular}{|l|c|l|}
\hline P value & Correlation co-efficient & Variable \\
\hline $\mathbf{0 . 6 5}$ & $\mathbf{0 . 0 9}$ & Picture naming noun \\
\hline $\mathbf{0 . 0 5 1}$ & $\mathbf{0 . 3 9}$ & Picture naming categories \\
\hline $\mathbf{0 . 1 3}$ & $\mathbf{0 . 3 1}$ & Picture naming profession \\
\hline $\mathbf{0 . 3 9}$ & $\mathbf{- 0 . 1 8}$ & Picture naming verb \\
\hline $\mathbf{0 . 7 5}$ & $\mathbf{- 0 . 0 7}$ & naming of no. \&days \\
\hline $\mathbf{0 . 4 6}$ & $\mathbf{- 0 . 1 6}$ & Sentence completion \\
\hline $\mathbf{0 . 9 9}$ & $\mathbf{- 0 . 0 0 4}$ & Description naming \\
\hline $\mathbf{0 . 7 4}$ & $\mathbf{0 . 0 7}$ & Total \\
\hline \multicolumn{2}{|c|}{$*=\mathrm{P}<0.05$ (significant) and ${ }^{* *}=\mathrm{P}<0.001$ (highly significant). } \\
\hline
\end{tabular}

\section{Discussion}

In this study, a new test for evaluation of word finding difficulty in children was designed to be more suitable for children at our environment at Sohag governorate. The test consists of 7 sections to cover most of items needed to be assessed e.g. nouns, professions, categories, verbs as well as sentence completion and description to allow thorough assessment. In sections (1) to 
(5), there are pictures of different semantic groups (body parts, vegetables, fruits, birds, animals, clothes, transportations, furniture, electric devices and private tools), categories, professions (jobs), verbs and shapes respectively. These pictures were chosen to be suitable for both urban and rural features at our governorate. When the pictures were chosen, these features were in mind in order not to expose the child to a picture he or she didn't encounter before or doesn't know. They were graduated in difficulty from common to less common objects to rare objects. Also, sentences of the sections (6) and (7) were chosen carefully and the point of familiarity (grading from common to rare) and the environmental factors were in mind during their design. The pictures graduated in difficulty or commonality to cover all items that the child deals with or faces in the daily life activities or in the environment.

The test was applied on 2 groups of subjects (group I and group II) with an age range of 5-10 years. This age range was chosen to be sure that the subject has sufficient language that allows proper evaluation and detection of word finding difficulty. The groups were divided into subgroups with age range from 5 years to 7 years and 6 months and with age range more than 7 years and 6 months to 10 years in order to get smaller age range for the subgroups and consequently getting more accurate results.

In this study, both groups were compared as regard age, gender and IQ. There were no significant difference between both groups. This means that age, gender and IQ have no important effect on the scores of different sections of the word finding difficulty test and the results are more likely linked to the language status rather than to the age, gender or IQ of the subject. These findings were in agreement with Jeffry and Coady (2013).

In the current study, there were highly significant differences in word finding difficulty test scores between group I and group II. These differences were evident in all sections of the test (as regard accuracy and speed on naming which is reflected on the score obtained by the subject). Jeffry and Coady (2013) found slower naming speed in 20 children with DLD (SLI) with mean age of 9 years, 8 months, compared to age controlled normal children.

It was found that naming speed in children with DLD (SLI) was slower compared to age controlled normal children. Studies indicated that children with DLD acquire their first words later than do their typically developing peers. They tend to learn words more slowly (Alt and Plante, 2006). For words that they already know, children with DLD exhibit lexical deficits in a variety of tasks. They are slower to recognize words than are age-matched typically developing children (Mainela et al., 2008). Furthermore, their performance in definition and drawing tasks suggested that their semantic representations of known words are less specified (Mainela et al., 2010).Together, these findings suggested that children with SLI have small vocabularies at any point in development, difficulty adding new words to their lexicons, and inefficient access to words that they know. Evidence supporting a lexical deficit is the finding that children with SLI tend to name pictures more slowly and less accurately than do their typically developing peers.

In a study done at Phoniatric unit, Ain Shams University by Adel et al., (2014) children with DLD were evaluated in order to determine if they really have a problem in naming speed 
in the preschool years. A group of DLD children diagnosed as specific language impairment (SLI) compared to a group of normal children. The naming speed was tested. The results of the group of SLI children were compared to age-matched group of normal children. There was a highly significant difference in all parameters with the SLI group scoring longer durations in each level and more errors than normal children.These findings are in agreement with findings of the current study.

In this study, there were highly significant differences in word finding difficulty test scores between subject and control subgroups in age range from 5 years to 7 years and 6 months and in age range more than 7 years and 6 months to 10 years. These differences were evident in all sections of the test. Similarly, Adel et al., 2014 found highly significant difference when each age subgroup of SLI (namely, 3-4 years and 4-5 years) was compared to their normal peers. This means that SLI children lag one year behind in naming speed results in relation to their normal peers at the age range of 3-4 years. This can be attributed to the linguistic abilities of the subject that helped him/her to know the item tested and name it quickly and accurately. Similar results of that research obtained in our study that proves the validity of our test.

Kail and Leonard (1986) suggested that children with language impairments have a less developed language system than chronological age controls, and, as a result, their language system has less elaborate semantic entries, which in turn affects word retrieval. On this basis, one would expect that naming by children with language difficulties to be dissimilar to chronological age controls.
A different explanation for the word finding difficulty of children with SLI was advanced by Kail (1994) who reported that these children are slower in responding to all types of stimuli and that this general reduction in processing speed accounts for their slow naming.Children with SLI also experience difficulties in accessing the phonological form of a word. Faust et al. (1997) investigated the tip-of-thetongue phenomenon in children with SLI who had word retrieval problems. The children had more tip-of-thetongue responses than chronological age matched controls, and they gave proportionally more incorrect phonological information when probed about the inaccessible target word. They were less likely to spontaneously name the target word, and were less accurate in reporting whether they knew the word.

In the current study, when the scores of different sections of the test of subgroup Ia and Ib were compared, there was highly significant difference in all sections of the test. Also, when the scores of different sections of the test of subgroup IIa and IIb were compared, there was highly significant difference in sections (1), (4), (5), (7) and total score with significant difference in section (6). As regard section (2) and (3), the difference didn't reach a significant level. This is because the score of both subgroups of DLD children was not high in these two sections of the test. This can be explained by the reason that the DLD children in both subgroups may not acquire the term of the category or profession needed to be named yet. So, when evaluated the children in both subgroups got a low score with no significant difference. Similar results was found by Adel et al., 2014.It was found that naming speed is a skill that correlated positively and in a highly significant manner in normal children 
aged 2-5 years. In the SLI group, the correlation was also positive with age but in a highly significant manner in the easiest level, significant only in the medium level, but non-significant in the most difficult level. The number of errors also followed the same pattern. It decreased with age in a highly significant manner in normal children, but in only a significant manner in SLI children.

In this study, correlation between receptive language age and the score of all sections of the word finding difficulty test in DLD children was done. There was significant positive correlation as regard section (1) with high significant positive correlation as regard section (2) and (3) with no significant correlation as regard other sections of the test. Also correlation between expressive language age and the score of all sections of the word finding difficulty test in DLD children was done. There was highly significant positive correlation as regard section (3) with no significant correlation as regard other sections of the test. When correlation between total language age and the score of sections of the test in DLD children was done, there was no significant correlation as regard all sections of the test.In a study by Jeffry and Coady (2013), the results suggested that naming times are related to expressive vocabulary. However, the two groups of children matched on vocabulary showed different sensitivity to a lexical variable (phonotactic probability), so vocabulary alone cannot account for the naming time results. Second, the younger children in the study were matched to the group of children with SLI on the basis of raw expressive vocabulary scores, but this matching criterion resulted in group differences in non verbal intelligence. The nonverbal scores for the group of vocabulary matched (VM) children were significantly higher than those for the group with SLI. This may potentially explain why the difference between children with SLI and VM controls was attenuated in the study. Children in the study named pictures with frequently occurring labels more quickly than they did those with infrequent labels.

\section{Conclusion}

Word finding difficulty test was designed to be applied in children. It consists of 7 sections. Its length and duration of application is suitable for children.It was found that children with DLD in the age range of 5-10 years score less than their age-matched normal children in different sections of the test.If naming problems are suspected, the word finding difficulty test should be applied for proper evaluation. Consequently proper intervention will be made and better results will be expected

\section{References}

1.Adel, H.M., Hegazi, M.A., Saber, A.S. (2014): Word Naming Speed in Specific Language Impairment Children. Ain Shams University, Cairo, Egypt.

2.Alt, M., and Plante, E.(2006). Factors that influence lexical and semantic fast mapping of young children with specific language impairment.Journal of Speech, Language, and Hearing Research,49,941-954.

3. Connor, L.T. and Obler, L.k. (2002): Anomia. In Ramachandron, V Encyclopedia of the human brain. New York: Academic Press.

4.Dockrell, J.E., Messer, D., George, R. and Wilson,G., (1998):Children's word finding difficultiesprevalence,presentation and naming problems.International Journal of language and Communicative disorders;33:445-454.

5.Faust, M., Dimitrovski, L. and Davidi, S. (1997): Naming difficulties in language disabled children: preliminary findings with the application of the tip 
of the tongue paradigm. Journal of Speech, language and Hearing. Research; 40:1026-1036.

6.German, D.J. (1998): Prevalence estimates for word finding difficulty in LD students. Implications for assessment/instructional accommodations. Paper presented at the Learning Disabilities Association, Washington.

7. German, D. J. (2000b) The Test of Word finding, Second Edition (TWF2). Austin, TX: Pro Ed

8. German, D.J. and Newman, R.S. (2005): Word Finding Based Oral Reading Errors, Paper presented at the International Congress of the Study of Child Language (ICSAL), Berlin, Germany.

9. Hanoura, M.A. (2002): Stanford-Binet Intelligence Test: Arabic Version. Cairo, Anglo Press.

10.Howard, D. and Gatehouse, C. (2006): Distinguishing semantic and lexical word retrieval deficits in people with aphasia. Aphasiology; 20(9):921-950.

11. Jeffry A and Coady (2013): Rapid Naming by Children with and without specific language impairment. Journal of Speech, Language, and Hearing Research; 56: 604-617.

12.Kail, R.(1994). A method for studying the generalized slowing hypothesis in children with specific language impairment. Journal of Speech and Hearing Research,37,418-421.

13.Kail, R.,\&Leonard, L. B.(1986).Word-finding abilities in language-impaired children (ASHA Monographs Number 25). Rockville,MD: American SpeechLanguage-Hearing Association.

14.Khedr,A.A., Hegazi, M.A., Saber, A.S.,Nassar,J.F.(2009):Word finding difficulties in communication disorders. Ain Shams University, Cairo, Egypt.
15.Kotby, M.N., Bassiouni, S., El Zomor, M. and Mohsen, E. (1985): Pilot study for standardization of an articulation test. Proc 10th Annu AinShams Med Congr, Cairo.

16.Kotby, M.N., Khairy, A., Baraka, M., Rifaie, N. and El Shoubary, A. (1995): Language testing of Arabic speaking children. Proceedings of the XXIII World Congress of International Association of Logopedics and Phoniatrics. Cairo; August 6-10.

17.Leonard, L. B.,Nippold, M. A., Kail, R. and Hale, C. A.(1983): Picture naming in language impaired children, Differentiating lexical storage from retrieval. Journal of Speech and Hearing Research, 26, 609-615.

18.Mainela-Arnold, E., Evans, J. L.,\& Coady, J. A.(2008). Lexical representations in children with SLI: Evidence from a frequencymanipulated gating task. Journal of Speech Language, and Hearing Research,51,381-393.

19.Mainela-Arnold, E., Evans, J. L.,\& Coady, J.(2010). . Explaining lexical semantic deficits in specific language impairment: The role of phonological similarity, phonological working memory,and lexical inhibition. Joumal of Speech,Language, and Hearing Research,53,1742-1756

20.Roach, A., Schwartz, M.F., Martin, N., Grewal, R.S. and Brecher, A.(1996): The Philadelphia Naming Test: Scoring and rationale. Clinical Aphasiology. ; 24:121-133.

21.Thompson, C.K., Lukic, S., King, M.C., Mesulam, M.M. and Weintraub, S. (2012): Verb and noun deficits in stroke-induced and primary progressive aphasia: The Northwestern Naming Battery. Aphasiology. ; 26(5): 632-655. 